\title{
Population comparison of right whale body condition reveals poor state of the North Atlantic right whale
}

\author{
Fredrik Christiansen ${ }^{1,2,3, *}$, Stephen M. Dawson, John W. Durban, Holly Fearnbach, \\ Carolyn A. Miller, Lars Bejder, Marcela Uhart, Mariano Sironi, Peter Corkeron, \\ William Rayment, Eva Leunissen, Eashani Haria, Rhianne Ward, Hunter A. Warick, \\ Iain Kerr, Morgan S. Lynn, Heather M. Pettis, Michael J. Moore \\ ${ }^{1}$ Aarhus Institute of Advanced Studies, Høegh-Guldbergs Gade 6B, 8000 Aarhus C, Denmark \\ ${ }^{2}$ Zoophysiology, Department of Biology, Aarhus University, C.F. Møllers Alle 3, 8000 Aarhus C, Denmark \\ ${ }^{3}$ Centre for Sustainable Aquatic Ecosystems, Harry Butler Institute, Murdoch University, Murdoch, 6150 Western Australia, Australia \\ The complete list of author addresses is in the Appendix
}

ABSTRACT: The North Atlantic right whale Eubalaena glacialis (NARW), currently numbering $<410$ individuals, is on a trajectory to extinction. Although direct mortality from ship strikes and fishing gear entanglements remain the major threats to the population, reproductive failure, resulting from poor body condition and sublethal chronic entanglement stress, is believed to play a crucial role in the population decline. Using photogrammetry from unmanned aerial vehicles, we conducted the largest population assessment of right whale body condition to date, to determine if the condition of NARWs was poorer than 3 seemingly healthy (i.e. growing) populations of southern right whales E. australis (SRWs) in Argentina, Australia and New Zealand. We found that NARW juveniles, adults and lactating females all had lower body condition scores compared to the SRW populations. While some of the difference could be the result of genetic isolation and adaptations to local environmental conditions, the magnitude suggests that NARWs are in poor condition, which could be suppressing their growth, survival, age of sexual maturation and calving rates. NARW calves were found to be in good condition. Their body length, however, was strongly determined by the body condition of their mothers, suggesting that the poor condition of lactating NARW females may cause a reduction in calf growth rates. This could potentially lead to a reduction in calf survival or an increase in female calving intervals. Hence, the poor body condition of individuals within the NARW population is of major concern for its future viability.

${ }^{*}$ Corresponding author: f.christiansen@aias.au.dk

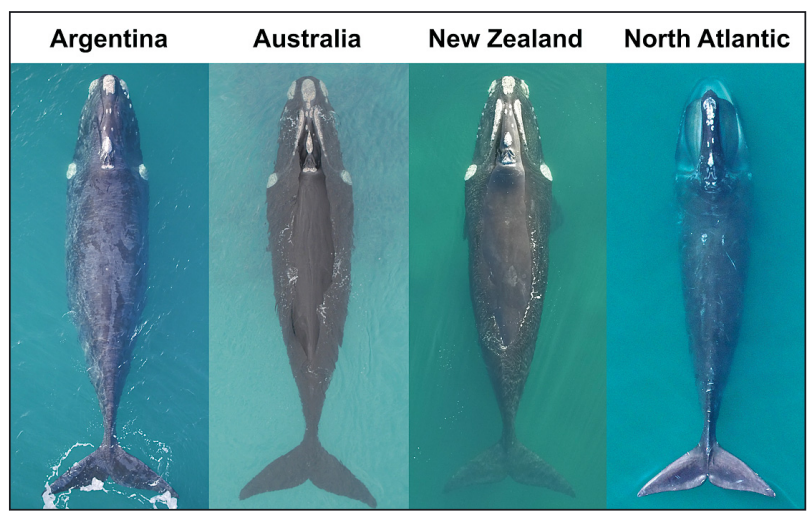

Three healthy southern right whales (left three photographs) next to a North Atlantic right whale (right) in visibly poorer body condition

Photos: Fredrik Christiansen (left \& center-left), Stephen $M$. Dawson (center-right), John W. Durban/Holly Fearnbach (right)

KEY WORDS: Baleen whale - Bioenergetics · Eubalaena · Morphometrics · Photogrammetry · Unmanned aerial vehicles

\section{INTRODUCTION}

Right whale populations around the world were severely depleted (some reduced to less than $5 \%$ of the original population size) by commercial whaling operations from the $11^{\text {th }}$ to the $20^{\text {th }}$ century in the North Atlantic (Aguilar 1986, Reeves et al. 1999) and during

(C) The authors 2020. Open Access under Creative Commons by Attribution Licence. Use, distribution and reproduction are unrestricted. Authors and original publication must be credited. 
the $19^{\text {th }}$ to $20^{\text {th }}$ century in the Southern hemisphere (Dawbin 1986, Jackson et al. 2016), as well as by illegal Soviet whaling in the Southern hemisphere in the 1950s to early 1970s (Yablokov 1994, Tormosov et al. 1998). Since the cessation of commercial whaling, the southern right whale Eubalaena australis (SRW) has been recovering at a relatively rapid pace throughout most of its range, and currently numbers in the tens of thousands globally (IWC 2013). The population growth rate during this time has been as high as $5.55 \%$ for Australia (Bannister 2016), 5-7 \% for New Zealand (Carroll et al. 2013) and 6.5\% for Argentina (Cooke et al. 2015), although the growth rate of the latter has slowed down substantially (Crespo et al. 2019).

In contrast, the recovery of the North Atlantic right whale E. glacialis (NARW) has been considerably slower, with a mean annual growth rate of $2.8 \%$ between 1990 and 2010 (Pace et al. 2017). More recent abundance estimates, between 2010 and 2015, indicate that the population has been declining at a rate of just under $1 \%$ per year (Pace et al. 2017). The rate of decline has been higher for females, which dropped at approximately $7 \%$ between 2010 and 2015, compared to about $4 \%$ for males over the same period (Pace et al. 2017). The situation for NARWs was further worsened by an unusual mortality event between 1 November 2016 and 31 December 2017, when at least 17 juvenile and adult right whales died as a result of entanglements and vessel strikes (NARWC 2018). In December 2015, prior to the 2017 mortalities, the species' abundance was estimated at 451 individuals, of which 186 were females. The best estimate as of the end of 2017 was 411 animals (Pettis et al. 2018). While fishing gear entanglements and ship strikes are the largest direct anthropogenic threats to the NARW population (Moore et al. 2004, Knowlton et al. 2012, van der Hoop et al. 2013, Kraus et al. 2016), reduced reproductive rate resulting from nutritional stress (i.e. poor body condition) has been hypothesised as a factor further contributing to the population decline (Kraus et al. 2001, Reeves et al. 2001, Schick et al. 2013, Rolland et al. 2016). The sublethal impacts of entanglement have also been modelled to significantly impact reproductive success (van der Hoop et al. 2017).

The effect of body condition on reproduction is well documented in both terrestrial (Albon et al. 1983, Loudon et al. 1983, Skogland 1984, Atkinson \& Ramsay 1995, Festa-Bianchet 1998) and marine mammals (Arnbom et al. 1997, Boltnev \& York 2001, Bowen et al. 2001, Wheatley et al. 2006). In baleen whales, female body condition influences fecundity (Lockyer 2007, Williams et al. 2013), foetal growth (Christiansen et al. 2014) and calf body condition
(Christiansen et al. 2016a). Like most baleen whales, right whales make annual migrations between highlatitude feeding grounds in summer and low-latitude breeding grounds in winter (Bannister et al. 1999). Females become sexually mature at around 9 yr old and give birth to a single calf at a time (Kraus et al. 2001, Cooke et al. 2003, Burnell 2008). They are 'capital' breeders, fasting during the winter breeding season, and thus have a finite amount of energy to invest in late pregnancy and lactation (Lockyer 1987, Stephens et al. 2009). Christiansen et al. (2018) showed in SRWs that maternal size (body length and condition) has a direct effect on the amount of energy that lactating females invest in their calves, which in turn dictates calf growth rates. When conditions are favourable, females generally have a 3 yr reproductive cycle consisting of $1 \mathrm{yr}$ of gestation, $1 \mathrm{yr}$ of lactation and $1 \mathrm{yr}$ of resting (to recover energy stores) (Best 1994). The mean calving interval for SRWs is close to this $3 \mathrm{yr}$ minimum, at $3.33 \mathrm{yr}$ in Australia (Burnell 2001), $3.31 \mathrm{yr}$ in New Zealand (Davidson et al. 2017) and between 2.96 and $3.24 \mathrm{yr}$ in Argentina (Marón et al. 2015). In contrast, since 2015, the mean calving interval for NARW females is $>7 \mathrm{yr}$ (Pettis et al. 2020), suggesting that they need several years longer to recover from a reproductive event. Apart from body condition having a direct effect on female reproductive success, it can also influence juvenile growth rates (Douhard et al. 2017) and the age of sexual maturation (Sigurjónsson et al. 1990), which could negatively influence population growth.

The aim of this study was to assess the body condition of the NARW. Although the population's body condition (based on visual assessment) has declined during the last 3 decades (Rolland et al. 2016), a comparison to healthy (growing) right whale populations is needed to assess its current status. Unfortunately, no historical data on NARW body condition exist to allow such a comparison. Instead, the best opportunity to assess the relative body condition of NARW comes from a comparison with their closest living relative, the SRW. We therefore compared the body condition of NARWs with 3 seemingly healthy (i.e. growing) populations of SRW in Australia, New Zealand and Argentina. Although we were comparing 2 different species of right whales (Rosenbaum et al. 2000, Gaines et al. 2005), which might differ in their body condition due to genetic differences, our rationale was that body condition, similar to most traits closely associated with fitness, shows low genetic variance relative to environmental variance (Mousseau \& Roff 1987, Kruuk et al. 2000). We also show that NARWs and SRWs are very similar in body shape, size and life 
history characteristics, which should facilitate comparison. Based on the lower population growth rate and longer calving interval of the NARW, our main hypothesis is that NARWs are in poorer body condition compared to SRWs. To help infer the potential effects of reduced body condition on different life history parameters, we split our analysis into different reproductive classes (calves, juveniles, adults and lactating females). We expected lactating females to overall have a higher body condition relative to the other reproductive classes, since they must have had sufficient energy reserves to complete gestation (Lockyer 1981, Christiansen et al. 2014). However, with NARWs being affected by numerous anthropogenic factors, we expected the body condition of lactating females to be significantly lower than for SRWs. In baleen whales, a lower maternal body condition has been shown to negatively influence calf growth rates (Christiansen et al. 2018) and body condition (Christiansen et al. 2016a). We therefore anticipated NARW calves to have a poorer body condition and/or a smaller body size (i.e. length) compared to SRW calves. Finally, with fishing gear entanglements affecting both juvenile and adult NARWs (NARWC 2018), we projected both reproductive classes to have a lower body condition compared to SRWs.

\section{MATERIALS AND METHODS}

\subsection{Data collection}

Aerial photographs of right whales were taken using non-invasive (Christiansen et al. 2016b) unmanned aerial vehicles (UAVs) in 4 locations: the
North Atlantic, Australia, New Zealand and Argentina (Fig. 1). Photographs of NARW lactating females and calves were collected on their calving grounds in Florida, USA, between 12 January and 22 February 2016 and 2017, while juvenile and adult NARWs were photographed on their feeding grounds in Cape Cod Bay, USA, between 21 March and 27 April 2016 and 2017 (Fig. 1). All SRWs were measured on their breeding grounds at the Head of Bight, Australia, between 25 June and 25 September 2016, the Auckland Islands, New Zealand, between 28 July and 14 August 2016, and in Península Valdés, Argentina, between 3 August and 12 November 2018.

In each location, multirotor UAVs were flown from either land (Australia and Argentina) and/or boats (North Atlantic, New Zealand and Argentina) above a surfacing whale at altitudes between 17.8 and $55.1 \mathrm{~m}$ (mean $=31.3 \mathrm{~m}, \mathrm{SD}=8.01$; Argentina $=$ $17.8-37.0 \mathrm{~m}$; Australia $=27.9-46.6 \mathrm{~m}$; New Zealand $=$ 17.9-51.3 m; North Atlantic $=26.8-55.1 \mathrm{~m}$ ), and vertical photographs were taken of the dorsal side of the whale (Fig. 2A). For the North Atlantic study site, an APH-22 hexacopter with an Olympus E-PM2 camera was used, while modified DJI Inspire 1 Pro quadcopters with Zenmuse X5 cameras were used in Australia, Argentina and New Zealand. Both UAV types were equipped with an Olympus M Zuiko $25 \mathrm{~mm}$ f1.8 lens to minimize picture distortion. Measurement accuracies of both the APH-22 and the Inspire 1 Pro systems have been estimated at 99.9\% (Durban et al. 2015, Dawson et al. 2017, Christiansen et al. 2018). Christiansen et al. (2018) further quantified the measurement errors of the Olympus $25 \mathrm{~mm}$ lens when flying at different altitudes ranging from 5 to $120 \mathrm{~m}$ and measuring a known sized object on land.

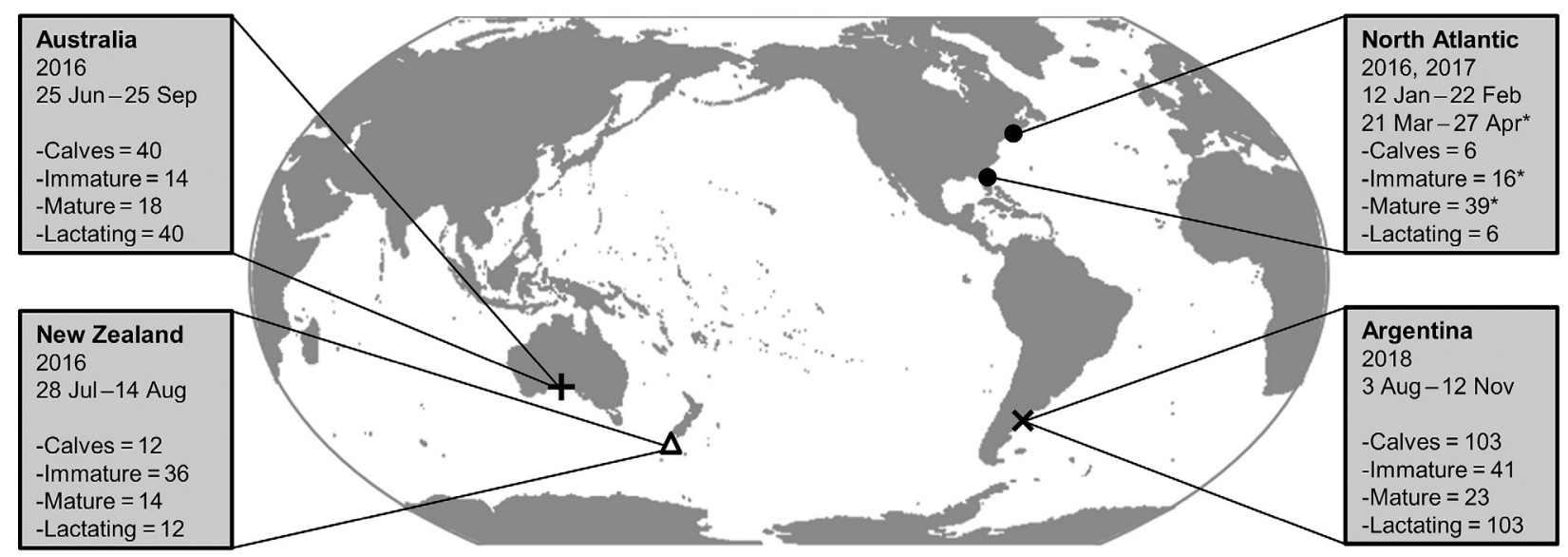

Fig. 1. Location of the 4 study regions, with sample sizes and dates of data collection provided for each location. All whales were measured on their breeding grounds, except for immature and mature North Atlantic right whales $\left({ }^{*}\right)$, which were measured on their feeding grounds (top filled circle for the North Atlantic) 
A

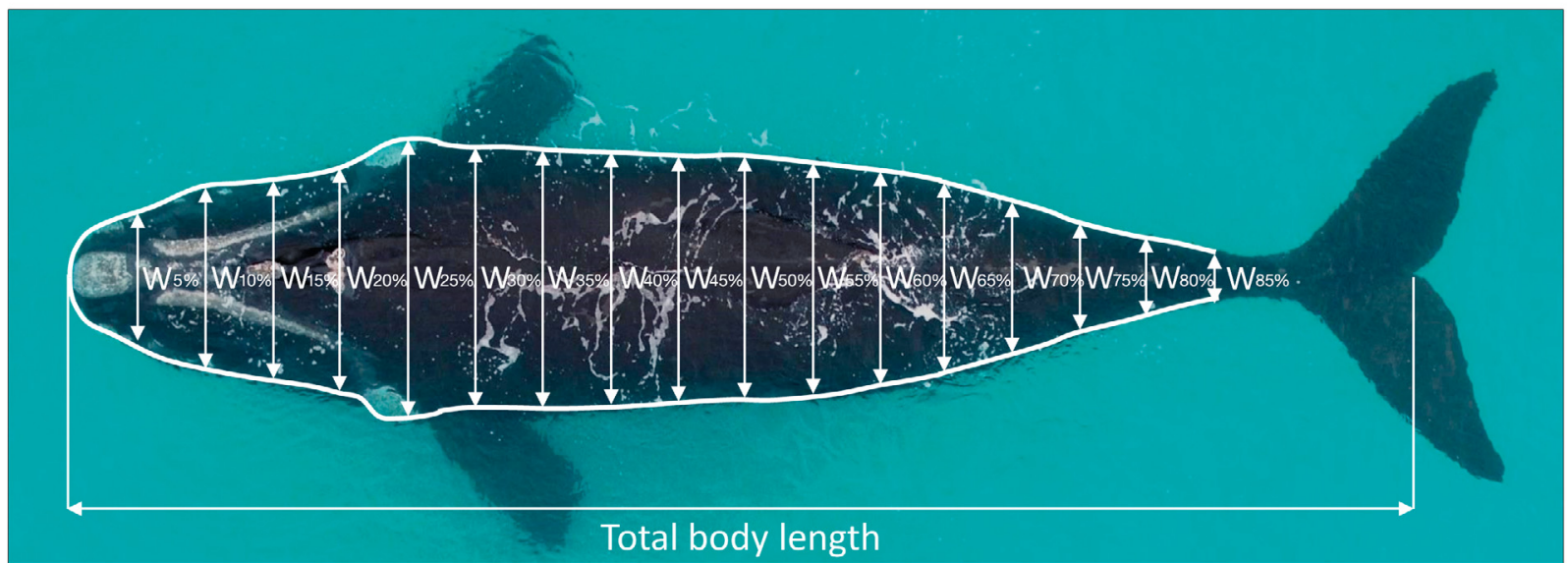

B

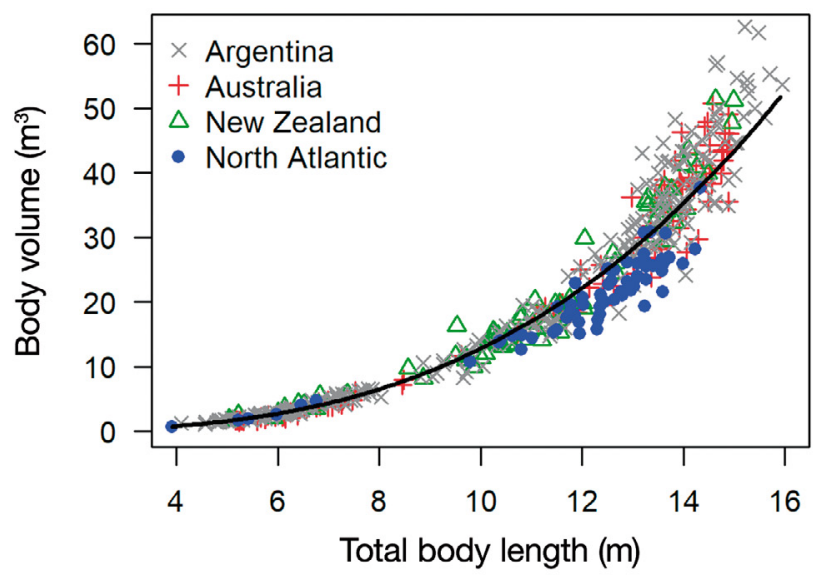

C

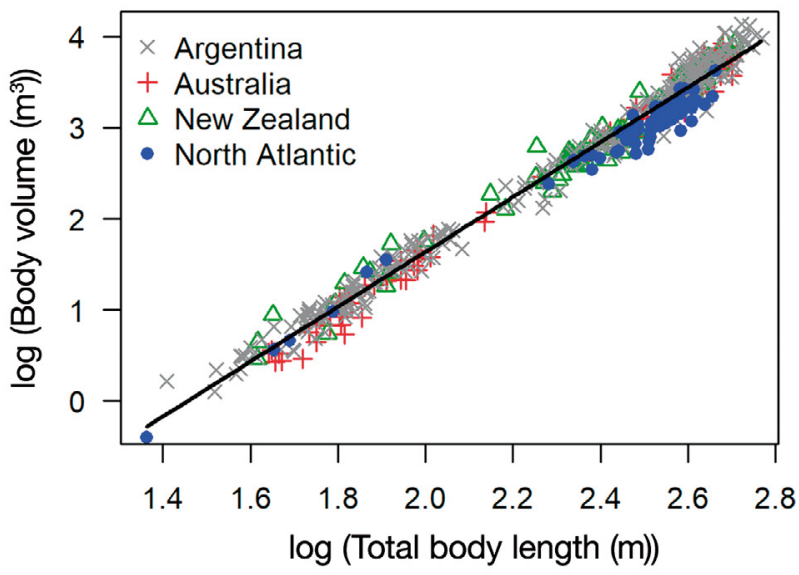

Fig. 2. (A) Example aerial photograph of a right whale used to measure body condition, showing the positions of the measurement sites used in the study. W: width. (B) Right whale body volume as a function of body length for the 4 sampled locations. The solid line represents the back-transformed fitted values of the linear model. (C) Log-log relationship between body volume and body length for the 4 sampled locations, with the solid line representing the fitted values of the linear model. $\mathrm{N}=523$ whales

Their results showed that within the altitude range used in this study (17.8 and $55.1 \mathrm{~m}$ ) the mean measurement error was $0.7 \mathrm{~cm}(\mathrm{SD}=0.5, \mathrm{n}=50)$ with a maximum of $1.6 \mathrm{~cm}$. Since the measurement errors were not influenced by the altitude of the UAV, differences in sampling altitude between locations did not bias measurements. When photographing whales, a camera gimbal ensured that the camera of the UAV was always facing down at a near-perfect $90^{\circ}$ angle. Only photographs of adequate quality, when the whale was lying flat at the surface, were used for analyses (for details, see Christiansen et al. 2018). From the aerial photographs, individual whales were identified based on the unique callosity patterns on their heads (Payne et al. 1983). The Australian, New Zealand and North Atlantic data sets included multi- ple measurements from the same individuals. To avoid pseudo-replication, only a single measurement for each whale was used, which was selected randomly (using a random number generator in R) from the best photographs of that individual. We judged this to be a less biased approach compared to using the average measurements from repeated photographs of the same individuals (taken over several days), as the latter might introduce temporal variation in body measurements, and also cause heterogeneity in measurement errors between individuals (animals with single or multiple measurements) and populations.

Following the protocol of Christiansen et al. (2018), each photograph was graded (given a score of 1 [good quality], 2 [medium quality] or 3 [poor quality]) 
on several attributes, including degree of body roll, degree of body arch, body pitch (vertically), body length measurability and body width measurability. Only photographs with a roll, arch or pitch $<3$ were used in the analyses. To account for variation in body length and width measurability between photographs, we ran a sensitivity analysis where the body length and width of each individual whale were randomly varied within the confidence interval given by its length and width measurability scores (for details, see Christiansen et al. 2018). By repeating this process 1000 times, and refitting the final models in the analyses, the effect of the length and width measurement errors on the model parameters could be evaluated (see Fig. S1 in the Supplement at www.int-res. com/articles/suppl/m640p001_supp.pdf).

\subsection{Morphometric measurements and classification of reproductive classes}

The total body length of the whales (tip of the lower jaw to the notch of the tail fluke) and their body widths (at $5 \%$ increments along the entire body axis of the animal), were measured (Fig. 2A), using a custom written graphical user interface (GUI) in MATLAB (Dawson et al. 2017). The GUI accounted for distortion of the camera lens through photogrammetric calibration (for details, see Dawson et al. 2017). All photographs were measured by a single experienced researcher, thus minimizing any potential interobserver bias. Image scale was established from the known focal length in combination with precise altitude data. For the North Atlantic data, altitude of the APH-22 was measured using an inbuilt GPS (mean error $=0.05 \mathrm{~m}$; Durban et al. 2015) or a LightWare $\mathrm{SF} 11 / \mathrm{C}$ laser range finder (mean error $=0.02 \mathrm{~m}$; Dawson et al. 2017). For the SRW populations, the altitude of the Inspire 1 Pro was measured using the same type of range finder. While the accuracy of the altimeters used might have differed slightly, the width to length ratio of the whales was not affected by this, and hence this did not bias the body condition estimates.

Each whale was classified into 1 of 4 reproductive classes: calves ( $<4$ mo of age), immature (juveniles), mature (non-lactating adults) and lactating females. Calves and lactating females were distinguished based on their close association with each other on the calving/breeding grounds. Immature and mature whales were separated based on their body length, using a threshold value of $12.0 \mathrm{~m}$, which was based on the body length of the smallest lactating female measured in this study $(11.72 \mathrm{~m})$. A NARW mother with an older calf ( $>4$ mo old), measured on the Cape Cod Bay feeding ground, was removed from the analyses. Similarly, adults with body volumes similar to or exceeding that of lactating females with newly born calves (calf body length $\sim 5 \mathrm{~m}$ ), were removed from the analyses as these likely represent late-stage pregnant females. The absolute and relative body width (body width/body length) of right whales at each measurement site was compared between locations and for each reproductive class, using linear models in R 3.5.3 (R Core Team 2019) (Figs. S2 \& S3).

From the body length and width measurements, body volume was calculated using the methods of Christiansen et al. (2018). By assuming a circular cross-sectional body shape, the body volume of the whales was estimated by dividing the body of the whale into 18 frustum segments (1 between each width measurement) and calculating the volume $\left(V_{s}\right)$ of each segment $s$ using the formula of a truncated cone (Christiansen et al. 2018):

$$
V_{S}=\frac{1}{3} \pi h\left(r^{2}+r R+R^{2}\right)
$$

where the height $(h)$ is given by the distance between width measurements $(5 \%$ of the body length), and the smaller $(r)$ and larger radii $(R)$ correspond to half of the smaller and larger width measurements, respectively (for details, see Christiansen et al. 2018). Total body volume ( $\left.V_{\text {Total }}\right)$ of the whales was then estimated by summing the volumes of the different frustum segments (Christiansen et al. 2018):

$$
V_{\text {Total }}=\sum_{s=1}^{S} V_{S}
$$

Similar to Christiansen et al. (2018), the body volume of immature, mature and lactating females was calculated between 25 (the end of the head region) and $80 \%$ of their body length, which corresponds to the metabolically most active region of baleen whales (Lockyer et al. 1985, Miller et al. 2012, Christiansen et al. 2013, 2016a, 2018). Since the width to length ratio of calves is known to increase across their entire body axis during the first month of their lives (Christiansen et al. 2018), the body volume of calves was calculated from the tip of their rostrum down to $80 \%$ of their body length.

\subsection{Body condition index}

An animal's body condition provides a measure of its energy balance, health and quality (Jakob et al. 
1996, Peig \& Green 2009, 2010). Although body condition can be expressed through any physiological index that represents an individual's energy reserves (Hanks 1981, Millar \& Hickling 1990), it generally refers to the relative size of energy stores compared with structural components (commonly the length) of the body (Green 2001). Consequently, an individual's body condition strongly influences its survival and reproductive success (Gaillard et al. 2000, CluttonBrock \& Sheldon 2010). Christiansen et al. (2018) showed that the body volume of lactating SRW females at the time they give birth will determine the amount of energy they invest in their calves (i.e. the rate of decline in maternal body volume), and consequently calf growth rates (i.e. rate of increase in calf body volume). Based on this, we calculated the body condition index (BCI) of individual right whales from the residuals of the log-log relationship (to account for non-linear relationships) between body volume and body length, divided by the expected (or predicted) body volume for the individual (to standardized BCI across body size, Christiansen et al. 2013, 2016a, 2018):

$$
\mathrm{BCI}_{i}=\frac{\mathrm{BV}_{\mathrm{obs}, i}-\mathrm{BV}_{\text {exp }, i}}{\mathrm{BV}_{\exp , i}}
$$

where $\mathrm{BV}_{\mathrm{obs}, i}$ is the observed body volume of whale $i$ in $\mathrm{m}^{3}$, and $\mathrm{BV}_{\text {exp, } i}$ is the expected body volume of whale $i$ in $\mathrm{m}^{3}$, given by the log-log relationship between body volume and body length:

$$
\log \left(\mathrm{BV}_{\mathrm{exp}, i}\right)=\alpha+\beta \times \log \left(\mathrm{BL}_{i}\right)
$$

where $\mathrm{BL}_{i}$ is the body length of whale $i$, and $\alpha$ and $\beta$ represent the intercept and slope parameters, respectively, of the linear relationship between body volume and body length for all locations combined.

A positive BCI means that an individual was in relatively better condition than an average individual of the same body length, whereas a negative BCI means that the individual was in relatively poorer condition. To demonstrate that our BCI was independent from the absolute size (length) of the individual, we calculated the body condition of all measured whales using both the absolute (body length and widths, in metres) and relative body morphometrics (body length and widths, in pixels). The 2 approaches yielded nearly identical BCIs $\left(F_{1,521}=739902, \mathrm{p}<0.001, \mathrm{R}^{2}=0.999\right.$, Fig. S4 $)$, and showed that our metric accounted for potential structural differences (i.e. body length) between animals. The BCI of each individual was calculated from the length-to-volume relationship of all meas- ured individuals. If we had modelled BCI separately for each reproductive class (i.e. fitting a separate length-to-volume model for each reproductive class) it would have resulted in a slight shift in the intercept (mean body condition) for each reproductive class, but would not have influenced the effect of location within each reproductive class (Fig. S5). Finally, although our BCI was based on a crosssectional sample of the population (a single measurement representing a single whale), it correlated strongly with the BCI calculated from repeated measurements of the same whales (available for the Australian data set, see Fig. S6).

\subsection{Differences in body condition between locations}

To determine if NARWs were in poorer body condition compared to the 3 southern populations, we developed linear models in R 3.5.3. Right whale body condition (response variable) was modelled as a function of location (explanatory variable). Separate models were run for each reproductive class (calves, immature, mature and lactating females).

During the breeding season, lactating females have finite energy reserves to support their own metabolic needs and the growth of their calf (Lockyer 2007, Christiansen et al. 2018). Consequently, lactating females decline in body condition through the breeding season as their calves grow in size (Christiansen et al. 2016a, 2018). To account for the temporal variation in body condition of lactating females (i.e. female body condition declining with increased calf length), calf body length was included as a covariate in the model. Similarly for calves, the effect of maternal body length and condition on calf body condition was investigated. Other covariates included day of the year (DOY; with the North Atlantic data converted to austral DOY by adding $183 \mathrm{~d}$ ) and body length. However, collinearity (high correlation) between location and DOY, as well as between location and body length, resulted in only location being included in the final model for juvenile and adult right whales. To investigate the effect of location on body length, separate linear models were developed for each reproductive class.

Model validation included testing for homogeneous residuals (by plotting model residuals against the fitted model values), examining normality of residuals (from frequency histograms of residuals) and influential points and outliers (by calculating leverage scores and Cook's distance, respectively). 


\subsection{Validation of cross-species comparison}

To enable comparison of the body condition of the NARW and the SRW, their physiology and life history need to be very similar, so that the genetic variance does not exceed the environmental variance. To validate our cross-species comparison, we therefore compared the body shape, size and life history characteristics of NARWs and SRWs (Table 1).

To compare the structural body shape of NARWs and SRWs, we first measured the relative body width of the whales, and compared their head (0-25\% body length from the rostrum) and tail regions (80-100\% body length from the rostrum). With both these areas being mainly structural (Brodie 1975), and not part of the metabolically active body area for right whales (between 25 and $80 \%$ of body length, Christiansen et al. 2018), any genetic difference in the external body width between species should be visible in those areas. We found no difference in the body width of the head or tail region of the whales (Table 1, Fig. S3). Further, although the site-specific body widths of NARWs and SRWs differed across the metabolically active body area of the whales, their overall body shapes were very similar (Fig. S3). Finally, Christiansen et al. (2019) showed that the relationship between body mass (or body volume) and length was very similar between NARWs (based on Fortune et al. 2012) and SRWs (from the Argentina population) (Table 1)

In regards to life history characteristics, Soviet catch data between 1951 and 1971 showed that female SRWs reach sexual maturity around $12.5 \mathrm{~m}$ in body length (Tormosov et al. 1998). Similarly, Sharp et al. (2019) classified NARW adults as individuals $>9$ yr of age, which, based on recent age-tolength curves, corresponds to a body length around $12.5 \mathrm{~m}$ (Table 1). Further, we found that the minimum body length of lactating SRWs in this study was $11.72 \mathrm{~m}$, which was very similar to the minimum body length of lactating NARWs, which was $11.86 \mathrm{~m}$ (Table 1). In regards to birth size, our smallest measured NARW calf was $3.9 \mathrm{~m}$ in body length (which is within their predicted birth range of $4.22 \pm 0.4 \mathrm{~m}$; Fortune et al. 2012), which was very similar to the smallest SRW calf at $4.1 \mathrm{~m}$ body length (Table 1). Huang et al. (2009) also presented similar calf weaning lengths ( $8.78 \mathrm{~m}$ vs. $8.26 \mathrm{~m}$ ) and female asymptotic lengths $(17.8 \mathrm{~m}$ vs. $16.6 \mathrm{~m})$ for NARWs and SRWs (Table 1).

\section{RESULTS}

The body volume of 523 right whales was successfully measured between 2016 and 2018 in the 4 study locations (Fig. 1). There was a strong linear relation-

Table 1. Comparison of body shape, size and life history characteristics between the North Atlantic right whale (NARW) and the southern right whale (SRW). BL: body length

\begin{tabular}{|c|c|c|c|}
\hline $\begin{array}{l}\text { Structural body shape/ } \\
\text { life history characteristic }\end{array}$ & NARW & SRW & Source \\
\hline $\begin{array}{l}\text { Relative width }(\% \mathrm{BL} \pm \mathrm{SE}) \text { of head } \\
(20 \% \text { BL from rostrum) }\end{array}$ & $\begin{array}{c}\text { Calf }=20.0 \pm 0.67 \\
\text { Immature }=20.1 \pm 0.21 \\
\text { Mature }=19.5 \pm 0.15 \\
\text { Lactating }=19.8 \pm 0.45\end{array}$ & $\begin{array}{c}\text { Calf }=20.4 \pm 0.28 \\
\text { Immature }=20.8 \pm 0.18 \\
\text { Mature }=20.8 \pm 0.22 \\
\text { Lactating }=20.9 \pm 0.13\end{array}$ & This study (Fig. S3) \\
\hline $\begin{array}{l}\text { Relative width }(\% \mathrm{BL} \pm \mathrm{SE}) \text { of tail } \\
(80 \% \text { BL from rostrum })\end{array}$ & $\begin{array}{c}\text { Calf }=5.5 \pm 0.15 \\
\text { Immature }=4.2 \pm 0.16 \\
\text { Mature }=4.3 \pm 0.10 \\
\text { Lactating }=3.6 \pm 0.19\end{array}$ & $\begin{array}{c}\text { Calf }=5.0 \pm 0.16 \\
\text { Immature }=4.0 \pm 0.08 \\
\text { Mature }=3.8 \pm 0.13 \\
\text { Lactating }=3.9 \pm 0.10\end{array}$ & This study (Fig. S3) \\
\hline Female length (m) at sexual maturity & 12.5 & 12.5 & $\begin{array}{l}\text { Tormosov et al. (1998), } \\
\text { Sharp et al. (2019) }\end{array}$ \\
\hline Minimum length $(\mathrm{m})$ of lactating females & 11.7 & 11.9 & This study \\
\hline Female asymptotic length $(\mathrm{m})$ & 17.8 & 16.6 & Huang et al. (2009) \\
\hline Minimum length (m) at birth & 3.9 & 4.1 & This study \\
\hline Length at weaning $(\mathrm{m})$ & 8.8 & 8.3 & Huang et al. (2009) \\
\hline Weight $(\mathrm{kg})$ at birth $(\mathrm{BL}=4 \mathrm{~m})$ & 940 & 870 & $\begin{array}{l}\text { Christiansen et al. (2019), } \\
\text { Fortune et al. (2012) }\end{array}$ \\
\hline Weight $(\mathrm{kg})$ at weaning $(\mathrm{BL}=8.5 \mathrm{~m})$ & 7,830 & 7,970 & $\begin{array}{l}\text { Christiansen et al. (2019), } \\
\text { Fortune et al. (2012) }\end{array}$ \\
\hline Weight $(\mathrm{kg})$ at sexual maturity $(\mathrm{BL}=12.0 \mathrm{~m})$ & 20,680 & 21,940 & $\begin{array}{l}\text { Christiansen et al. (2019), } \\
\text { Fortune et al. (2012) }\end{array}$ \\
\hline
\end{tabular}


ship between body volume (BV) and body length (BL) on the log-log scale $\left(F_{1,521}=28953, \mathrm{p}<0.001\right.$, $\mathrm{R}^{2}=0.982$, Fig. 2C):

$$
\log \left(\mathrm{BV}_{\exp , i}\right)=-4.38+3.01 \times \log \left(\mathrm{BL}_{i}\right)
$$

Lactating females in the North Atlantic were in poorer body condition compared to the southern populations $\left(F_{3,156}=5.11, \mathrm{p}=0.002, \mathrm{R}^{2}=0.072\right.$, Fig. 3 ; and see Fig. S7 and model 6 in Table S1). The body condition of lactating females from all 4 populations decreased as the calf grew in size (i.e. body length) through the breeding season $\left(F_{1,156}=42.02\right.$, $\mathrm{p}<0.001$, $\mathrm{R}^{2}=0.197$ ), at a rate of $6.62 \% \mathrm{BCI} \mathrm{m}{ }^{-1}$ calf length (Fig. 4D, model 6 in Table S1). If we account for the body length of their calves (i.e. fix calf length to $6.0 \mathrm{~m}$ in the model), the body condition of lactating NARW females $($ mean $=-9.4 \%, \mathrm{SE}=4.8)$ was $20.5,24.9$ and
$17.6 \%$ units lower compared to lactating SRW females in Australia (mean $=11.2 \%, \mathrm{SE}=2.1$ ), New Zealand (mean $=15.6 \%, \mathrm{SE}=3.4$ ) and Argentina $($ mean $=8.3 \%, \mathrm{SE}=6.5)$, respectively (Figs. $3 \& 4 \mathrm{D})$.

The body length analyses showed that lactating NARW females (mean $=13.2 \mathrm{~m}, \mathrm{SE}=0.29$ ) were on average 96, 54 and $48 \mathrm{~cm}$ shorter $\left(F_{3,157}=5.07, \mathrm{p}=\right.$ $0.002, \mathrm{R}^{2}=0.088$ ) than Australian (mean $=14.2 \mathrm{~m}$, $\mathrm{SE}=0.32$ ), Argentinian (mean $=13.8 \mathrm{~m}, \mathrm{SE}=0.30$ ) and New Zealand females (mean $=13.7 \mathrm{~m}, \mathrm{SE}=$ 0.36), respectively (Fig. 4C). Consequently, the mean absolute body volume (mean $=27.9 \mathrm{~m}^{3}, \mathrm{SE}=2.90$ ) of lactating NARWs was significantly $\left(F_{3,157}=6.10\right.$, p < $\left.0.001, R^{2}=0.104\right)$ lower than for SRWs in Australia $\left(\right.$ mean $\left.=39.9 \mathrm{~m}^{3}, \mathrm{SE}=3.11\right)$, New Zealand $($ mean $=$ $38.1 \mathrm{~m}^{3}, \mathrm{SE}=3.56$ ) and Argentina (mean $=36.1 \mathrm{~m}^{3}$, $\mathrm{SE}=2.99)$, at a magnitude of $11.99,10.22$ and $8.22 \mathrm{~m}^{3}$, respectively.
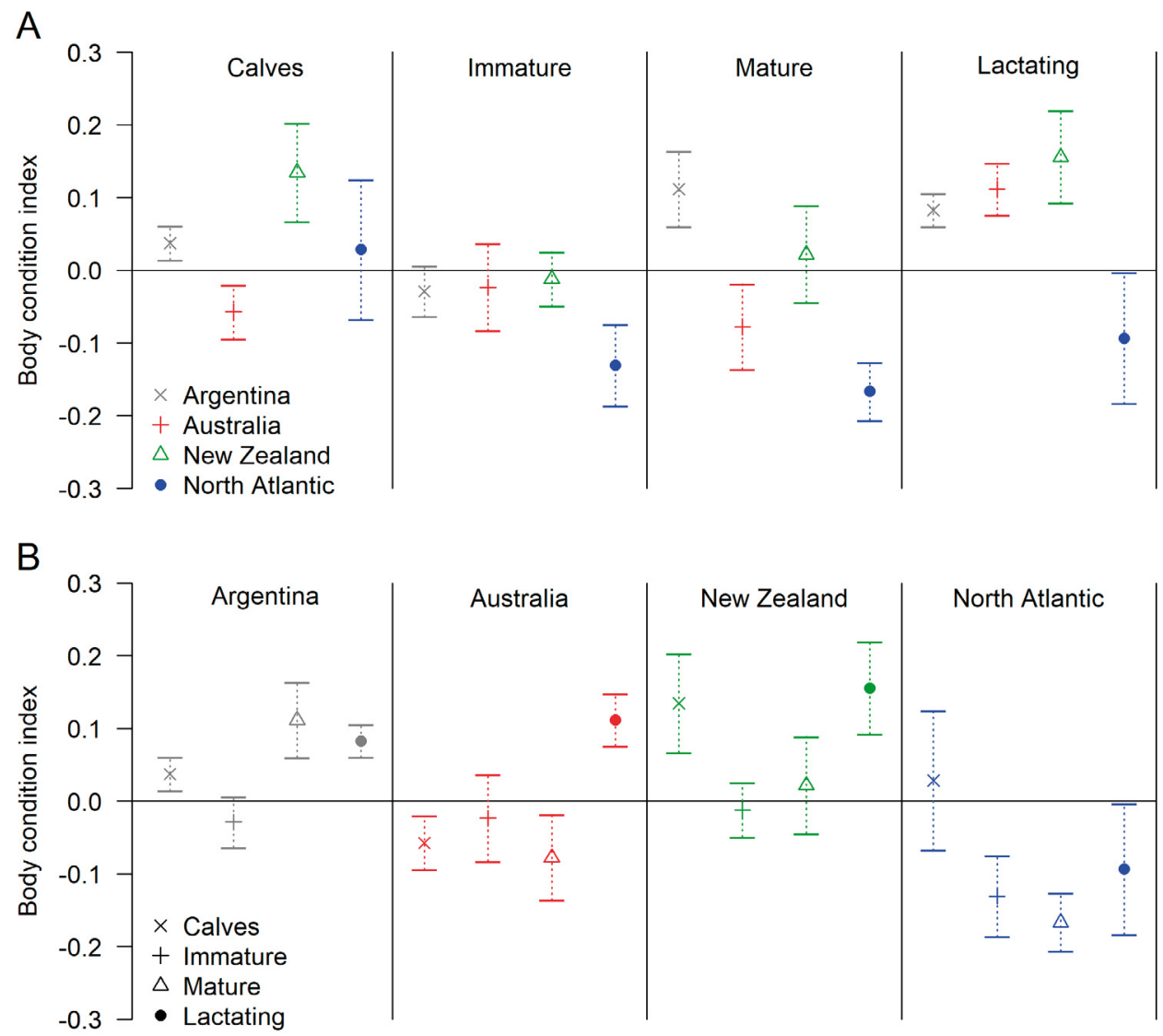

Fig. 3. (A) Predicted body condition values from the best fitting models for right whale calves (model 1 in Table S2 in the supplement), immature whales, mature whales and lactating females (model 6 in Table S1), as a function of location. (B) Predicted body condition values for right whales from Argentina, Australia, New Zealand and the North Atlantic, as a function of reproductive class. Error bars represent $95 \%$ confidence intervals. All whales were measured on their calving/breeding grounds, except for immature and mature North Atlantic right whales, which were measured on their feeding grounds. For lactating females, the full model also included calf body length as an explanatory variable, with maternal body condition declining significantly with calf body length (Fig. 4C). In the partial effect plot shown here, calf length was fixed at $6 \mathrm{~m}$, which represents the mean body length of calves measured in this study. Sample sizes for all reproductive classes are given in Fig. 1 
A

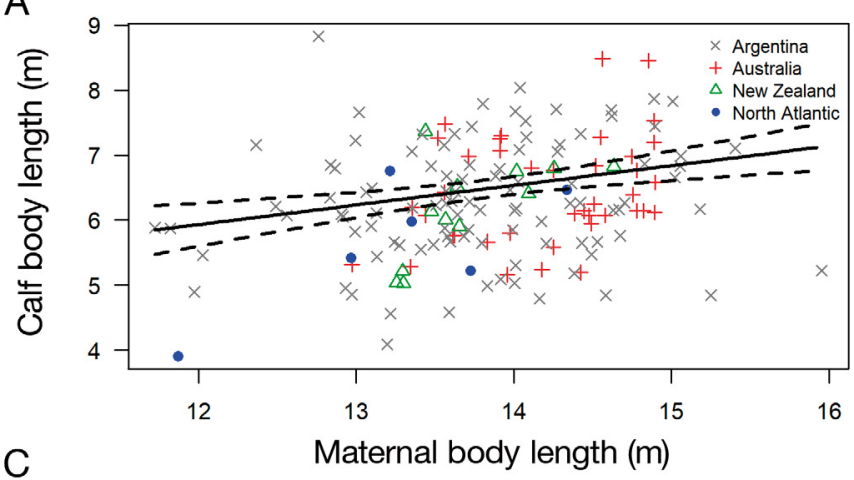

C

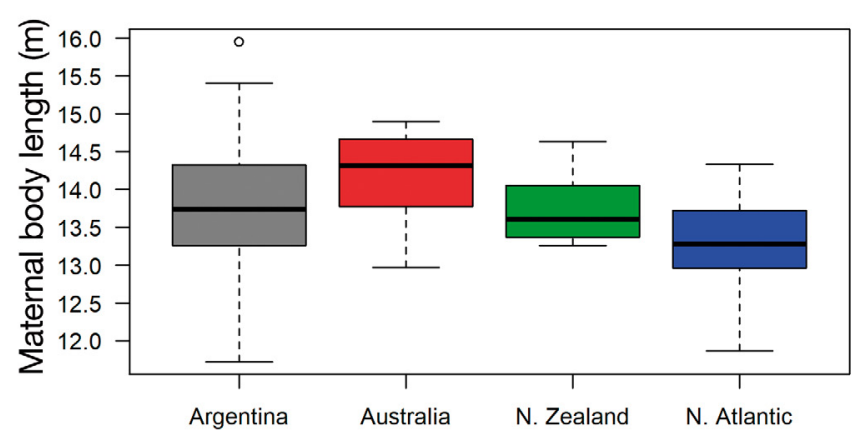

Location
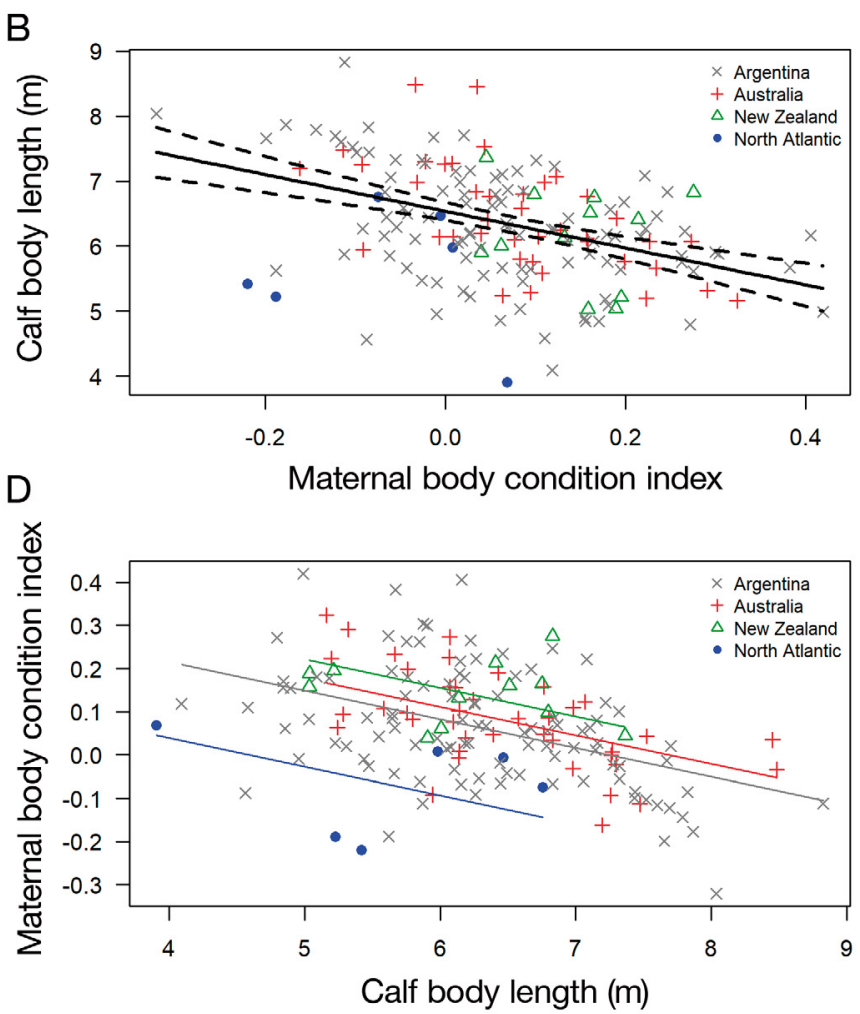

Fig. 4. (A) Partial effect plot of right whale calf length as a function of maternal body length, with maternal body condition fixed at 0 . (B) Partial effect plot of right whale calf length as a function of maternal body condition, with maternal body length fixed at $14.0 \mathrm{~m}$ (the mean length of lactating females in the data set). The solid lines represent the fitted values of the best fitting linear model (Model 6 in Table S3) and the dashed lines represent $95 \%$ confidence intervals. (C) Maternal body length between locations. (D) Right whale maternal body condition as a function of calf body length for different locations. The solid lines represent the fitted values of the best fitting linear model (model 6 in Table S1). N = 161 lactating females with calves

NARW calves did not show signs of being in poorer condition compared to SRW calves, and the body length of calves (a rough proxy for time since birth) did not vary significantly between locations. Further, the day of sampling did not vary significantly between NARWs (after correcting the time of year with $183 \mathrm{~d}$ between the Northern and Southern hemisphere) and SRWs in Australia and New Zealand. Instead, we found that Australian calves (mean $=-5.7 \%, \mathrm{SE}=$ $2.2)$ were significantly $\left(F_{3,157}=9.93, \mathrm{p}<0.001, \mathrm{R}^{2}=\right.$ 0.159, Fig. 3; Fig. S7 and Table S2) thinner than New Zealand (mean $=13.5 \%, \mathrm{SE}=3.7)$ and Argentinian calves (mean $=3.7 \%, \mathrm{SE}=1.2$ ).

Body length of calves was positively related to the length of their mothers $\left(F_{1,158}=12.5, \mathrm{p}<0.001, \mathrm{R}^{2}=\right.$ $0.061)$ at a rate of $0.302 \mathrm{~m}(\mathrm{SE}=0.082)$ per $\mathrm{m}$ increase in maternal length (Fig. 4A; model 6 in Table S3). In addition, maternal body condition was negatively correlated (slope parameter $=-2.82 \mathrm{~m}, \mathrm{SE}=0.474$ ) with calf body length $\left(F_{1,158}=35.5, \mathrm{p}<0.001, \mathrm{R}^{2}=\right.$ 0.172 ), since maternal body condition decreased as the calf grew in body length (Fig. 4B; model 6 in
Table S3). The full model explained $23.3 \%$ of the variance in the data.

There was a difference in body condition of mature right whales (males and non-lactating females) between locations $\left(F_{3,90}=25.06, \mathrm{p}<0.001, \mathrm{R}^{2}=0.455\right.$, Fig. 3; Figs. S7 \& S8), with North Atlantic adults $($ mean $=-16.7 \%, \mathrm{SE}=2.0)$ being 27.9, 18.9 and $8.9 \%$ units lower in condition compared to individuals from Argentina $($ mean $=11.2 \%, \mathrm{SE}=3.3)$, New Zealand $($ mean $=2.2 \%, \mathrm{SE}=4.0)$ and Australia (mean $=$ $-7.8 \%, \mathrm{SE}=3.6$ ), respectively (Fig. 3). In addition to being in poorer condition, the average body length of mature NARW (mean $=12.9 \mathrm{~m}, \mathrm{SE}=0.13$ ) was lower $\left(F_{3,90}=6.07, \mathrm{p}<0.001, \mathrm{R}^{2}=0.168\right)$ compared to Argentina (mean $=13.9 \mathrm{~m}, \mathrm{SE}=0.22)$, New Zealand $($ mean $=13.4 \mathrm{~m}, \mathrm{SE}=0.26)$ and Australia (mean $=$ $13.3 \mathrm{~m}, \mathrm{SE}=0.24)$ (Fig. S9B).

We found that immature NARWs $($ mean $=-13.1 \%$, $\mathrm{SE}=2.9)$ were in significantly poorer condition $\left(F_{3,103}=\right.$ $4.30, p=0.007, R^{2}=0.111$, Fig. 3; Fig. S7) than juveniles in New Zealand (mean $=-1.2 \%, \mathrm{SE}=3.4$ ), Australia (mean $=-2.4 \%, \mathrm{SE}=4.2$ ) and Argentina 
(mean $=-2.9 \%, \mathrm{SE}=3.4)$. On average, the BCI of immature NARWs was 11.9, 10.7 and $10.2 \%$ units lower than juveniles from New Zealand, Australia and Argentina, respectively (Fig. 3). Juvenile NARWs (mean $=11.2 \mathrm{~m}, \mathrm{SE}=0.19)$ were on average longer $\left(F_{3,103}=7.03, \mathrm{p}<0.001, \mathrm{R}^{2}=0.170\right)$ than juveniles in Argentina (mean $=10.5 \mathrm{~m}, \mathrm{SE}=0.22$ ) and New Zealand (mean $=10.5 \mathrm{~m}, \mathrm{SE}=0.22$ ), and similar in size to Australian juveniles $($ mean $=11.3, \mathrm{SE}=0.27$ ) (Fig. S9A).

The results from our sensitivity analysis showed that all body condition model parameter values were robust to measurement errors resulting from differences in picture quality (body length and width measurability) (Fig. S1).

\section{DISCUSSION}

Like most baleen whales, right whales rely heavily on stored energy for reproduction, particularly during lactation (Lockyer 1981, Miller et al. 2012, Christiansen et al. 2018). While the body condition of NARWs has declined during the last 3 decades (Rolland et al. 2016), this study provides the first comparison with healthy (i.e. growing) SRW populations. In agreement with our main hypothesis, we found that NARW juveniles, adults and lactating females were all in significantly poorer body condition compared to the SRW populations. Our results were robust to measurement errors resulting from variation in picture quality (body length and width measurability).

The largest difference in body condition was for lactating females, with NARW females being on average $21 \%$ units lower than the 3 SRW populations. To put this into perspective, the body condition of lactating females decreased by about $19 \%$ units during the first 3 mo of lactation, assuming a calf growth rate of $3.2 \mathrm{~cm} \mathrm{~d}^{-1}$ (Christiansen et al. 2018). This early lactation period is considered the most energetically costly part of the reproductive cycle in baleen whales, since females are still relying on stored energy reserves during this time, while their calf is growing rapidly in size (Lockyer 1981, Miller et al. 2012, Christiansen et al. 2016a, 2018). In support of this, we found that the body condition of lactating females was generally better than that of juveniles and adults (Fig. 3). A compromised body condition during this critical time period means that NARW females have considerably less energy available to invest in their calves, which is known to negatively influence calf growth rates (Christiansen et al. 2018). While we did not have data to directly investigate calf growth rates for NARWs, we were able to inves- tigate the relationship between maternal body condition and calf length (Fig. 4D). We found that the absolute maternal cost of producing a similar sized calf (the slope parameter) was similar across populations, while the absolute maternal body condition at a given calf length (the intercept parameter) was significantly lower for NARW females. Assuming that NARW calves were growing at a slower rate compared to SRW calves, the observed difference in maternal condition could be due to a difference in the age of calves, with NARW calves being relatively older at a given body length compared to SRW calves. With NARW females having less energy reserves available to invest in their calf, this could result in them having to wean their calf at a smaller size. While weaning size is positively correlated to pup survival in pinnipeds (McMahon et al. 2000), this relationship is unknown in baleen whales. Alternatively, NARW females might compensate for their lower rate of offspring investment by extending the lactating period longer into the succeeding feeding season, when they are able to supplement their own body condition (and hence also their offspring investment) by concurrent feeding. While this strategy would likely result in a longer inter-calving interval for NARW females, since they would need more time to replenish their energy stores, it would not lead to a reduction in calf survival.

Lactating NARW females were also shorter in body length than the 3 southern populations. This was not the result of morphological differences (different asymptotic body lengths) between the 2 species, since whaling and stranding records show no species difference in body length (Tormosov et al. 1998, Moore et al. 2004, Huang et al. 2009, Fortune et al. 2012). With the absolute body volume of right whales being largely determined by their body length (Christiansen et al. 2018), lactating NARW females likely have less energy available to invest in their calves, which again will negatively affect calf growth rates. If we use Christiansen et al.'s (2018) relationship between maternal investment (rate of body volume loss) and maternal body length and condition for SRW in Australia, the magnitude of difference for lactating NARW (20.5\% unit lower body condition and $96 \mathrm{~cm}$ shorter body length) equates to a loss in maternal rate of investment of $50 \%$ (rate of decline in maternal body volume: North Atlantic $=0.063 \mathrm{~m}^{3} \mathrm{~d}^{-1}$; Australia: $0.126 \mathrm{~m}^{3} \mathrm{~d}^{-1}$ ). Determining the lower threshold in body condition at which lactating females will no longer be able to energetically support their calves should be the aim of future research, as well as identifying the threshold below which fertility 
(the probability of a female becoming pregnant) and pregnancy (the ability to complete gestation) is significantly compromised.

Despite the smaller size and poorer body condition of their mothers, NARW calves did not show signs of being in poorer condition compared to SRW calves. This is contrary to our hypothesis, which were based on the findings of Christiansen et al. (2016a), who reported a positive relationship between calf body condition and maternal body condition in humpback whales Megaptera novaeangliae. While this lack of effect could be due to a difference in the timing of sampling between locations, this is unlikely since the body length of calves (a rough proxy for time since birth) did not vary significantly between locations. It hence seems that a reduction in maternal body condition in right whales does not lead to a reduction in calf body condition, although it could still be suppressing calf growth in length.

We found that Australian calves had a significantly lower body condition compared to the other SRW populations. This was unexpected, since lactating females in Australia had similar body condition as females in New Zealand and Argentina (Fig. 3), and so we anticipated their calves to have similar condition. However, the lower body condition of Australian calves does not seem to be correlated with lower calf survival, since the population is growing at a similar rate $(5.55 \%$, Bannister 2016) to the New Zealand population (5-7\%, Carroll et al. 2013), and also has similar inter-calving intervals (Australia: 3.33 yr, Burnell 2001; New Zealand: 3.31 yr, Davidson et al. 2017). Further, only $4.2 \%$ of all measured calving intervals in Australia were 2 yr (Charlton 2017), an indication that females lost their calf early in lactation (Marón et al. 2015), compared to $8.9 \%$ in New Zealand (Davidson et al. 2017). It thus seems that the body condition of calves, within the range of values observed in this study, is not linked to their survival. Logically, calves should starve to death if their body condition falls below a critical limit where they can no longer afford to maintain homeostasis. However, assuming that their mothers can support them with sufficient energy, in the form of milk, to support their basic metabolic needs, baleen whale calves do not necessarily need to build up large fat reserves to survive. Instead, the lower body condition (higher surface area to volume ratio) of Australian calves might be an adaptation to the relatively warmer waters (lower heat loss) experienced on their breeding grounds $\left(15^{\circ} \mathrm{C}\right.$, sea surface temperature on 1 August, www.meteoblue.com) compared to New Zealand $\left(6.1-7.7^{\circ} \mathrm{C}\right.$, Rayment et al. 2015) and
Argentina $\left(11^{\circ} \mathrm{C}\right)$. In contrast, juveniles, adults and lactating females all rely on their own energy reserves during the breeding season, and so their survival and reproductive success is likely to be more closely linked to their body condition, whereas heat loss is likely to be less important due to their overall larger body size (lower surface area to volume ratio) and thicker blubber layer (more insulation).

Similar to lactating females, mature NARWs were in poorer body condition and smaller in size (i.e. body length) than the 3 SRW populations. Miller et al. (2011, 2012) found a similar difference in blubber thickness and body width of NARWs during the summer feeding season and SRWs in South Africa during the winter breeding season. The observed difference could be due to variations in the timing of sampling, with NARW adults being sampled early in their summer feeding season (when their energy reserves are still low from the previous breeding season) while SRW adults were measured during their winter breeding season (when they still have much of their energy reserves remaining). However, the magnitude of the difference in body condition between NARW and SRW adults in our study (Argentina = $27.9 \%$ units, Australia $=8.9 \%$ units, New Zealand $=$ $18.9 \%$ units) was similar or exceeded the observed variation in body condition within locations (95\% confidence range: Argentina $=15.2 \%$, Australia $=$ $9.3 \%$, New Zealand $=13.6 \%$, North Atlantic $=5.6 \%$ ), suggesting that variation in the time of sampling alone cannot explain the observed difference in body condition of adults between locations (Fig. 3). Further, had the NARW adults been measured towards the end of the feeding season (when they are at their peak body condition), the fact that they are still in poorer BCI compared to SRW adults is even more alarming. Repeated sampling of NARW and SRW adults on their feeding grounds, to determine the rate of fattening, is needed to accurately quantify the magnitude of the difference in BCI between adults from the 2 species.

From the measured mature NARWs of known sex, $36.1 \%$ (13 of 36 ) were females, which, based on their reproductive cycle, should have been either in a pregnant or resting state (non-pregnant, non-lactating). A reduction of body reserves in pregnant females can result in less energy available for the foetus, which in minke whales Balaenoptera acutorostrata has been shown to result in smaller (i.e. shorter) foetuses (Christiansen et al. 2014). However, given that no NARW calves were born in the 2017-2018 breeding season (NARWC 2018), we can conclude that the measured adult females in this study were either 
resting, had a failed pregnancy or lost their calf shortly after giving birth (before they could be sighted). In resting females, lower body condition suggests that females are taking longer to recover from reproduction and nursing than right whales in other populations. This could help explain the substantially longer calving interval of NARW females $(>7 \mathrm{yr}$ ) versus the SRW populations ( 3.3 yr) (Burnell 2001, Cooke et al. 2003, Davidson et al. 2017, Pettis et al. 2020). By combining aerial photogrammetry (to determine $\mathrm{BCI}$ ) and breath sampling (to determine reproductive status), future research should aim to assess whether a reduction in the BCI of NARW females is negatively affecting their fertility (their ability to become pregnant), pregnancy (their ability to complete gestation), offspring survival (their ability to energetically support their calf) and/or the time of recovery (their ability to deposit energy) from calving.

As for the adult whales, the lower body condition of immature NARWs could be partly due to variations in the timing of sampling between the North Atlantic and the southern populations. Younger NARW juveniles (1-4 yr) have also been found to have lower body condition (i.e. blubber thickness) compared to older juveniles (5-8 yr) (Miller et al. 2011). Potential age differences between locations are unlikely to explain the lower body condition of juvenile NARWs in this study, which on average were longer than juveniles in Argentina and New Zealand, and similar in size to Australian juveniles. Although the implication for vital rates is hard to determine, poorer body condition in juvenile NARWs could reduce the energy available for growth. This, in turn, could delay sexual maturation, which in baleen whales is strongly influenced by body size (Sigurjónsson et al. 1990). All else being equal, delayed sexual maturation would act to slow the population growth rate. A comparison of length-at-age growth curves between locations would help determine if NARWs are growing at a slower rate compared to the southern populations. This highlights the value of long-term monitoring projects with well-studied photo-identified individuals, for which age can be accurately determined.

With the NARWs being genetically isolated from the SRWs (Rosenbaum et al. 2000, Gaines et al. 2005), it is possible that some of the observed difference in BCI between the 2 species derives from genetic divergence and local adaptations to different environmental conditions (e.g. different water temperature and prey availability). Although traits closely associated with fitness, such as body condition, generally show low heritabilities (Mousseau \& Roff 1987, Kruuk et al. 2000), the genetic component of variance in body condition can still be significant (Réale et al. 1999, Merilä et al. 2001). Further, differences in salinity and prey depth between locations (feeding grounds) could influence the optimal body shape (fat to muscle ratio) to achieve neutral buoyancy during foraging (Narazaki et al. 2018). However, our findings show that the structural body shape of NARWs and SRWs is very similar, while published records demonstrate similar body sizes and life history characteristics of the 2 species (Tormosov et al. 1998, Huang et al. 2009, Sharp et al. 2019). Further, our data show that the body condition (and hence volume) needed to produce a similar-sized offspring was the same for lactating females across populations (Fig. 4D), suggesting that the body energy content was similar across species and locations. Finally, differences in water temperature between locations (both on the breeding and feeding grounds) could influence the optimal body shape (and hence BCI) for minimizing heat loss. While this could explain the observed difference in body condition between right whale calves, heat loss is unlikely to lead to a population difference in body condition of juveniles and adult whales, due to their significantly larger body size (lower surface area to volume ratio and thicker blubber layer), and ability to tolerate a wide variation in temperatures across their spatial range (between subtropical and subpolar zones).

The observed differences in body condition between the NARW and the SRW populations are most likely to result from differences in the exposure to anthropogenic factors. While the 3 SRW populations examined reside in relatively remote and unimpacted environments, the home range of the NARW overlaps with heavily developed coastal areas, the greatest lobster and crab trap and line densities and some of the world's busiest shipping lanes (Moore 2019). Despite management actions, ship strikes remain responsible for ongoing right whale mortalities in the North Atlantic (Moore et al. 2004, Knowlton et al. 2012, van der Hoop et al. 2013, Sharp et al. 2019); however, morbidity and mortality due to entanglement has become the predominant source of diagnosed trauma to NARWs since 2010 (NOAA 2018). This increasing entanglement in fishing gear is a major threat to NARWs; more than $83 \%$ of individuals carry scars from at least 1 entanglement, and $15.5 \%$ of the population is entangled every year (Knowlton et al. 2012). The additional drag, buoyancy and impeded foraging ability caused by various fishing gear leads to significant increases in the energy expenditure of right whales (Cassoff et al. 2011, van der Hoop et al. 2016, 2017). The cumula- 
tive energetic costs and stress resulting from repetitive and prolonged interactions with fishing gear can lead to substantial reductions in body condition (Rolland et al. 2012, Schick et al. 2013, Pettis et al. 2017, van der Hoop et al. 2017), which could result in reproductive failure and even death (Moore et al. 2004, Robbins et al. 2015, Rolland et al. 2016). Anthropogenic noise (e.g. from shipping) increases stress in NARWs, which carries energetic costs (Rolland et al. 2012).

Finally, climate-associated changes in right whale prey (the copepod Calanus finmarchicus) availability and distribution in the North Atlantic are believed to reduce the rate of energy intake, body condition and consequent calving rates (Miller et al. 2011, MeyerGutbrod et al. 2015, Meyer-Gutbrod \& Greene 2018). The smaller absolute body size (i.e. body length) of NARW adults and lactating females further suggests that the high mortality rate of females in the North Atlantic might have skewed their age range to a significantly lower average age than in SRWs (Pace et al. 2017). This would deprive NARW females of the advantage of larger size as shown by Christiansen et al. (2018). The 2017-2018 NARW breeding season highlighted the severity of the situation, when not a single calf was born into the population (NARWC 2018). Unless their situation improves soon, the ongoing decline of NARWs will result in them becoming another of the growing list of cetaceans (including vaquita Phocoena sinus, Pennisi 2017; Maui dolphin Cephalorhynchus hectori maui, Pala 2017; Gulf of Mexico Bryde's whale Balaenoptera edeni, Corkeron \& Kraus 2018) at serious risk of extinction.

Acknowledgements. Research permits: North Atlantic: NOAA 17355-01; Australia: DEWNR M26501-2 \& MR00082-3-V; New Zealand: Department of Conservation 50094-MAR; Argentina: Sub Secretaría de Conservación y Áreas Protegidas 43-SsCyAP/18 and Dirección de Fauna y Flora Silvestres 106/2018.SsG-M.P. Animal ethics permits: North Atlantic: Woods Hole Oceanographic Institution Institutional Animal Care and Use Committee; Australia and Argentina: Murdoch University O2819/16. UAV permits: North Atlantic: FAA MOU 2016-ESA-3-NOAA; Australia: 1-YC6NP-03. Funding: North Atlantic: NOAA NA14OAR4320158; Australia: US Office of Naval Research Marine Mammals Program (Award No. N00014-17-1-3018), the World Wildlife Fund for Nature Australia and a Murdoch University School of Veterinary and Life Sciences Small Grant Award; New Zealand: New Zealand Antarctic Research institute (NZARI 2016-1-4), Otago University and NZ Whale and Dolphin Trust; Argentina: National Geographic Society (Grant number: NGS379R-18). Thanks to: North Atlantic: NOAA's Office of Marine and Aircraft Operations and Aircraft Operations Center, D. LeRoi and W. Perryman for technical support; Australia: Aboriginal Lands Trust, Yalata Land Management and Far
West Coast Aboriginal Corporation for access to Aboriginal lands, and C. Charlton and F. Vivier for help in the field; this paper represents HIMB and SOEST contribution numbers 1788 and 10919; New Zealand: Crew and expedition members on board 'Polaris II'; Argentina: J. Graham, M. Ricciardi, A. Fernández Ajó, M. Di Martino, C. Adrian Diaz and R. Soley for help in the field, the Ferro family for access to their property and Instituto de Conservación de Ballenas for logistical support. Finally, we thank P. Palsbøll and 3 anonymous reviewers for their constructive comments which helped to improve this manuscript.

\section{LITERATURE CITED}

Aguilar A (1986) A review of old Basque whaling and its effect on the right whales (Eubalaena glacialis) of the North Atlantic. Rep Int Whaling Comm 10:191-199

Albon SD, Mitchell B, Staines BW (1983) Fertility and body weight in female red deer: a density-dependent relationship. J Anim Ecol 52:969-980

Arnbom T, Fedak MA, Boyd IL (1997) Factors affecting maternal expenditure in Southern elephant seals during lactation. Ecology 78:471-483

Atkinson SN, Ramsay MA (1995) The effects of prolonged fasting of the body composition and reproductive success of female polar bears (Ursus maritimus). Funct Ecol 9: 559-567

Bannister JL (2016) Monitoring population dynamics of 'western' right whales off southern Australia 2015-2018. Report to the Marine Biodiversity Hub, National Environmental Science Programme, University of Tasmania, Hobart

Bannister JL, Pastene LA, Burnell SR (1999) First record of movement of a southern right whale (Eubalaena australis) between warm water breeding grounds and the Antarctic Ocean, south of $60^{\circ} \mathrm{S}$. Mar Mamm Sci 15: 1337-1342

Best PB (1994) Seasonality of reproduction and the length of gestation in southern right whales Eubalaena australis. J Zool (Lond) 232:175-189

* Boltnev AI, York AE (2001) Maternal investment in northern fur seals (Callorhinus ursinus): interrelationships among mothers' age, size, parturition date, offspring size and sex ratios. J Zool (Lond) 254:219-228

Bowen WD, Iverson SJ, Boness DJ, Oftedal OT (2001) Foraging effort, food intake and lactation performance depend on maternal mass in a small phocid seal. Funct Ecol 15: 325-334

Brodie PF (1975) Cetacean energetics, an overview of intraspecific size variation. Ecology 56:152-161

Burnell SR (2001) Aspects of the reproductive biology and behavioral ecology of right whales off Australia. J Cetacean Res Manag 2:89-102

Burnell SR (2008) Estimates of demographic parameters of southern right whales off Australia. Rep SC/60/BRG12. International Whaling Commission, Cambridge

Carroll EL, Childerhouse SJ, Fewster RM, Patenaude NJ and others (2013) Accounting for female reproductive cycles in a superpopulation capture-recapture framework. Ecol Appl 23:1677-1690

* Cassoff RM, Moore KM, McLellan WA, Barco SG, Rotstein DS, Moore MJ (2011) Lethal entanglement in baleen whales. Dis Aquat Org 96:175-185

Charlton CM (2017) Population demographics of southern right whales (Eubalaena australis) in Southern Australia. 
PhD thesis, Curtin University, Bentley

Christiansen F, Vikingsson GA, Rasmussen MH, Lusseau D (2013) Minke whales maximise energy storage on their feeding grounds. J Exp Biol 216:427-436

Christiansen F, Víkingsson GA, Rasmussen MH, Lusseau D (2014) Female body condition affects foetal growth in a capital breeding mysticete. Funct Ecol 28:579-588

* Christiansen F, Dujon AM, Sprogis KR, Arnould JPY, Bejder L (2016a) Noninvasive unmanned aerial vehicle provides estimates of the energetic cost of reproduction in humpback whales. Ecosphere 7:e01468

Christiansen F, Rojano-Doñate L, Madsen PT, Bejder L (2016b) Noise levels of multi-rotor unmanned aerial vehicles with implications for potential underwater impacts on marine mammals. Front Mar Sci 3:277

Christiansen F, Vivier F, Charlton C, Ward R, Amerson A, Burnell S, Bejder L (2018) Maternal body size and condition determine calf growth rates in southern right whales. Mar Ecol Prog Ser 592:267-281

Christiansen F, Sironi M, Moore MJ, Di Martino M and others (2019) Estimating body mass of free-living whales using aerial photogrammetry and 3D volumetrics. Methods Ecol Evol 10:2034-2044

Clutton-Brock T, Sheldon BC (2010) Individuals and populations: the role of long-term, individual-based studies of animals in ecology and evolutionary biology. Trends Ecol Evol 25:562-573

Cooke J, Rowntree V, Payne R (2003) Analysis of inter-annual variation in reproductive success of South Atlantic right whales (Eubalaena australis) from photo-identifications of calving females observed off Península Valdés, Argentina, during 1971-2000. Rep SC/55/O23. International Whaling Commission, Cambridge

Cooke J, Rowntree V, Sironi M (2015) Southwest Atlantic right whales: interim updated population assessment from photo-ID collected at Peninsula Valdez, Argentina. Rep SC/66a/BRG/23. International Whaling Commission, Cambridge

Corkeron P, Kraus SD (2018) Baleen whale species on brink of extinction for first time in 300 years. Nature 554:169

* Crespo EA, Pedraza SN, Dans SL, Svendsen GM, Degrati M, Coscarella MA (2019) The southwestern Atlantic southern right whale, Eubalaena australis, population is growing but at a decelerated rate. Mar Mamm Sci 35:93-107

Davidson AR, Rayment W, Dawson SM, Webster T, Slooten E (2017) Estimated calving interval for the New Zealand southern right whale (Eubalaena australis). N Z J Mar Freshw Res 52:372-382

Dawbin WH (1986) Right whales caught in waters around south-eastern Australia and New Zealand during the nineteenth and early twentieth centuries. Rep Int Whaling Comm 10:261-268

Dawson SM, Bowman MH, Leunissen E, Sirguey P (2017) Inexpensive aerial photogrammetry for studies of whales and large marine animals. Front Mar Sci 4:366

* Douhard F, Gaillard JM, Pellerin M, Jacob L, Lemaître JF (2017) The cost of growing large: costs of post-weaning growth on body mass senescence in a wild mammal. Oikos 126:1329-1338

* Durban JW, Fearnbach H, Barrett-Lennard LG, Perryman WL, Leroi DJ (2015) Photogrammetry of killer whales using a small hexacopter launched at sea. J Unmanned Veh Syst 3:131-135

Festa-Bianchet M (1998) Condition-dependent reproductive success in bighorn ewes. Ecol Lett 1:91-94
Fortune SME, Trites AW, Perryman WL, Moore MJ, Pettis HM, Lynn MS (2012) Growth and rapid early development of North Atlantic right whales (Eubalaena glacialis). J Mammal 93:1342-1354

Gaillard JM, Festa-Bianchet M, Delorme D, Jorgenson J (2000) Body mass and individual fitness in female ungulates: bigger is not always better. Proc R Soc B 267: 471-477

Gaines CA, Hare MP, Beck SE, Rosenbaum HC (2005) Nuclear markers confirm taxonomic status and relationships among highly endangered and closely related right whale species. Proc R Soc B 272:533-542

*Green AJ (2001) Mass/length residuals: measures of body condition or generators of spurious results? Ecology 82: $1473-1483$

Hanks J (1981) Characterization of population condition. In: Fowler CW, Smith T (eds) Dynamics of large mammal populations. John Wiley, New York, NY, p 47-73

Huang SL, Chou LS, Ni IH (2009) Comparable length at weaning in cetaceans. Mar Mamm Sci 25:875-887

International Whaling Commission (2013) Report of the workshop on southern right whales. Doc SC/65A/Rep05. International Whaling Commission, Cambridge

Jackson JA, Carroll EL, Smith TD, Zerbini AN, Patenaude NJ, Baker CS (2016) An integrated approach to historical population assessment of the great whales: case of the New Zealand southern right whale. R Soc Open Sci 3: 150669

Jakob EM, Marshall SD, Uetz GW (1996) Estimating fitness: a comparison of body condition indices. Oikos 77:61-67

Knowlton AR, Hamilton PK, Marx MK, Pettis HM, Kraus SD (2012) Monitoring North Atlantic right whale Eubalaena glacialis entanglement rates: a $30 \mathrm{yr}$ retrospective. Mar Ecol Prog Ser 466:293-302

Kraus SD, Hamilton PK, Kenney RD, Knowlton AR, Slay CK (2001) Reproductive parameters of the North Atlantic right whale. J Cetacean Res Manag (Spec Issue) 2:231-236

Kraus SD, Kenney RD, Mayo CA, McLellan WA, Moore MJ, Nowacek DP (2016) Recent scientific publications cast doubt on North Atlantic right whale future. Front Mar Sci 3:137

Kruuk LEB, Clutton-Brock TH, Slate J, Pemberton JM, Brotherstone S, Guinness FE (2000) Heritability of fitness in a wild mammal population. Proc Natl Acad Sci USA 97:698-703

Lockyer C (1981) Estimation of the energy costs of growth, maintenance and reproduction in the female minke whale, (Balaenoptera acutorostrata), from the Southern hemisphere. Doc SC/32/Mi19. The Scientific Committee of the International Whaling Commission, Cambridge

Lockyer C (1987) The relationship between body fat, food resource and reproductive energy costs in North Atlantic fin whales (Balaenoptera physalus). Symp Zool Soc Lond 57:343-361

Lockyer C (2007) All creatures great and smaller: a study in cetacean life history energetics. J Mar Biol Assoc UK 87: 1035-1045

Kockyer CH, McConnell LC, Waters TD (1985) Body condition in terms of anatomical and biochemical assessment of body fat in North Atlantic fin and sei whales. Can J Zool 63:2328-2338

Loudon ASI, McNeilly AS, Milne JA (1983) Nutrition and lactational control of fertility in red deer. Nature 302: 145-147

Marón CF, Rowntree VJ, Sironi M, Uhart M, Payne RS, 
Adler FR, Seger J (2015) Estimating population consequences of increased calf mortality in the southern right whales off Argentina. Rep SC/66a/BRG/1. International Whaling Commission, Cambridge

McMahon CR, Burton HR, Bester MN (2000) Weaning mass and the future survival of juvenile southern elephant seals, Mirounga leonina, at Macquarie Island. Antarct Sci 12:149-153

* Merilä J, Kruuk LEB, Sheldon BC (2001) Natural selection on the genetical component of variance in body condition in a wild bird population. J Evol Biol 14:918-929

* Meyer-Gutbrod EL, Greene CH (2018) Uncertain recovery of the North Atlantic right whale in a changing ocean. Glob Chang Biol 24:455-464

*Meyer-Gutbrod EL, Greene CH, Sullivan PJ, Pershing AJ (2015) Climate-associated changes in prey availability drive reproductive dynamics of the North Atlantic right whale population. Mar Ecol Prog Ser 535:243-258

Millar JS, Hickling GJ (1990) Fasting endurance and the evolution of mammalian body size. Funct Ecol 4:5-12

Miller CA, Reeb D, Best PB, Knowlton AR, Brown MW, Moore MJ (2011) Blubber thickness in right whales Eubalaena glacialis and Eubalaena australis related with reproduction, life history status and prey abundance. Mar Ecol Prog Ser 438:267-283

Miller CA, Best PB, Perryman WL, Baumgartner MF, Moore MJ (2012) Body shape changes associated with reproductive status, nutritive condition and growth in right whales Eubalaena glacialis and E. australis. Mar Ecol Prog Ser 459:135-156

Moore MJ (2019) How we can all stop killing whales: a proposal to avoid whale entanglement in fishing gear. ICES J Mar Sci 76:781-786

Moore MJ, Knowlton AR, Kraus SD, McLellan WA, Bonde RK (2004) Morphometry, gross morphology and available histopathology in North Atlantic right whale (Eubalaena glacialis) mortalities (1970-2002). J Cetacean Res Manag 6:199-214

Mousseau TA, Roff DA (1987) Natural selection and heritability of fitness components. Heredity 59:181-197

Narazaki T, Isojunno S, Nowacek DP, Swift R and others (2018) Body density of humpback whales (Megaptera novaengliae [sic]) in feeding aggregations estimated from hydrodynamic gliding performance. PLOS ONE 13: e0200287

NOAA (2018) North Atlantic right whale (Eubalaena glacialis) stock assessment report. Natl Ocean Atmos Adm:13-29. www.fisheries.noaa.gov/webdam/download/ 82311292

NARWC (North Atlantic Right Whale Consortium) (2018) Identification Database 09/04/2018. North Atlantic Right Whale Consortium, Anderson Cabot Cent Ocean Life New Engl Aquarium, Boston, MA

Pace RM III, Corkeron PJ, Kraus SD (2017) State-space mark-recapture estimates reveal a recent decline in abundance of North Atlantic right whales. Ecol Evol 7: 8730-8741

Pala C (2017) New Zealand's endemic dolphins are hanging by a thread. Science 355:559

Payne R, Brazier O, Dorsey EM, Perkins JS, Rowntree VJ, Titus A (1983) External features in southern right whales (Eubalaena australis) and their use in identifying individuals. In: Payne R (ed) Communication and behavior of whales. Westview Press, Boulder, CO, p 371-445

Peig J, Green AJ (2009) New perspectives for estimating body condition from mass/length data: the scaled mass index as an alternative method. Oikos 118:1883-1891

*Peig J, Green AJ (2010) The paradigm of body condition: a critical reappraisal of current methods based on mass and length. Funct Ecol 24:1323-1332

Pennisi E (2017) After failed rescue effort, rare porpoise in extreme peril. Science 358:851

Pettis HM, Rolland RM, Hamilton PK, Knowlton AR, Burgess EA, Kraus SD (2017) Body condition changes arising from natural factors and fishing gear entanglements in North Atlantic right whales Eubalaena glacialis. Endang Species Res 32:237-249

Pettis HM, Pace RM, Hamilton PK (2018) North Atlantic Right Whale Consortium 2018 Annual Report Card. North Atlantic Right Whale Consortium, Boston, MA. www.narwc.org/uploads/1/1/6/6/116623219/2018report _cardfinal.pdf

Pettis HM, Pace RM, Hamilton PK (2020) North Atlantic Right Whale Consortium 2019 Annual Report Card. North Atlantic Right Whale Consortium, Boston, MA. www.narwc.org/uploads/1/1/6/6/116623219/2019report final.pdf

R Core Team (2019) R: a language and environment for statistical computing. R Foundation for Statistical Computing, Vienna

Rayment WJ, Dawson S, Webster T (2015) Breeding status affects fine-scale habitat selection of southern right whales on their wintering grounds. J Biogeogr 42:463-474

Kéale D, Festa-Bianchet M, Jorgenson JT (1999) Heritability of body mass varies with age and season in wild bighorn sheep. Heredity 83:526-532

Reeves R, Breiwick J, Mitchell E (1999) History of whaling and estimated kill of right whales, Balaena glacialis, in the northeastern United States, 1620-1924. Mar Fish Rev 61:1-36

Reeves RR, Rolland RM, Clapham PJ (2001) Causes of reproductive failure in North Atlantic right whales: new avenues of research. Report of a workshop held 26-28 April 2000, Falmouth, Massachusetts. Ref Doc 01-16. Northeast Fisheries Science Center, Woods Hole, MA

Kobbins J, Knowlton AR, Landry S (2015) Apparent survival of North Atlantic right whales after entanglement in fishing gear. Biol Conserv 191:421-427

Rolland RM, Parks SE, Hunt KE, Castellote M and others (2012) Evidence that ship noise increases stress in right whales. Proc R Soc B 279:2363-2368

Kolland RM, Schick RS, Pettis HM, Knowlton AR, Hamilton PK, Clark JS, Kraus SD (2016) Health of North Atlantic right whales Eubalaena glacialis over three decades: from individual health to demographic and population health trends. Mar Ecol Prog Ser 542:265-282

Rosenbaum HC, Brownell RL Jr, Brown MW, Schaeff C and others (2000) World wide genetic differentiation of Eubalaena: questioning the number of right whale species. Mol Ecol 9:1793-1802

* Schick RS, Kraus SD, Rolland RM, Knowlton AR and others (2013) Using hierarchical Bayes to understand movement, health, and survival in the endangered North Atlantic right Whale. PLOS ONE 8:e64166

* Sharp SM, McLellan WA, Rotstein DS, Costidis AM and others (2019) Gross and histopathologic diagnoses from North Atlantic right whale Eubalaena glacialis mortalities between 2003 and 2018. Dis Aquat Org 135:1-31

Sigurjónsson J, Halldórsson SD, Konráðsson A (1990) New information on age and reproduction in minke whales 
(Balaenoptera acutorostrata) in Icelandic waters. Doc SC/42/NHMi27. The Scientific Committee of the International Whaling Commission, Noordwijkerhout

Skogland T (1984) The effects of food and maternal conditions on fetal growth and size in wild reindeer. Rangifer 4:39-46

Stephens PA, Boyd IL, McNamara JM, Houston AI (2009) Capital breeding and income breeding: their meaning, measurement, and worth. Ecology 90:2057-2067

Tormosov DD, Mikhaliev YA, Best PB, Zemsky VA, Sekiguchi K, Brownell RL Jr (1998) Soviet catches of southern right whales Eubalaena australis, 1951-1971. Biological data and conservation implications. Biol Conserv 86:185-197

van der Hoop JM, Moore MJ, Barco SG, Cole TVN and others (2013) Assessment of management to mitigate anthropogenic effects on large whales. Conserv Biol 27:121-133

van der Hoop JM, Corkeron P, Kenney J, Landry S, Morin D,
Smith J, Moore MJ (2016) Drag from fishing gear entangling North Atlantic right whales. Mar Mamm Sci 32: 619-642

*van der Hoop J, Corkeron P, Moore M (2017) Entanglement is a costly life-history stage in large whales. Ecol Evol 7: 92-106

Wheatley KE, Bradshaw CJA, Davis LS, Harcourt RG, Hindell MA (2006) Influence of maternal mass and condition on energy transfer in Weddell seals. J Anim Ecol 75: 724-733

Williams R, Vikingsson GA, Gislason A, Lockyer C, New L, Thomas L, Hammond PS (2013) Evidence for densitydependent changes in body condition and pregnancy rate of North Atlantic fin whales over four decades of varying environmental conditions. ICES J Mar Sci 70: 1273-1280

* Yablokov AV (1994) Validity of whaling data. Nature 367: 108

Appendix. Complete list of authors' addresses

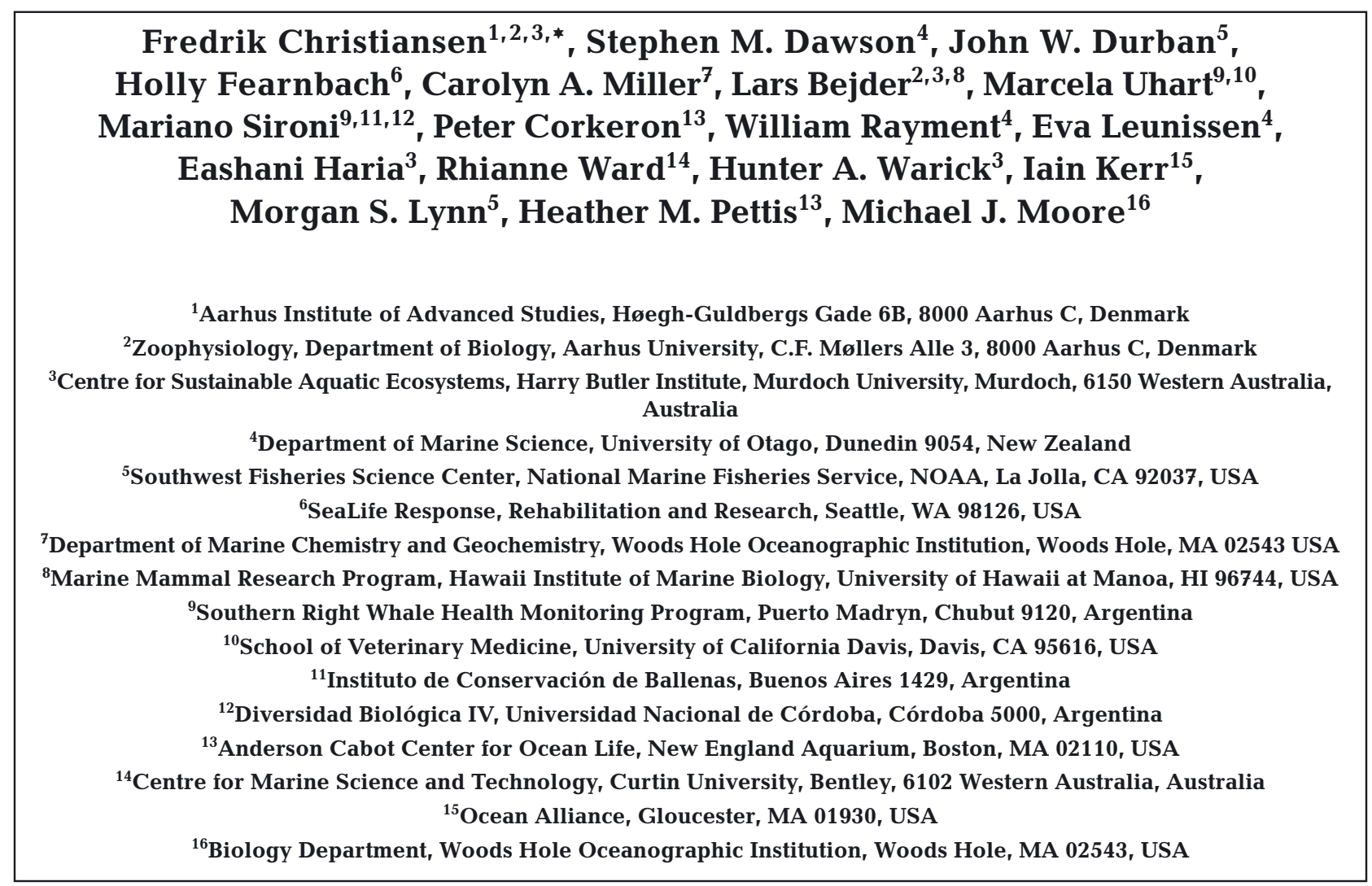

Editorial responsibility: Per Palsbøll, Groningen, The Netherlands
Submitted: June 17, 2019; Accepted: March 16, 2020

Proofs received from author(s): April 17, 2020 